\title{
A Contrastive Study of the Gaps in the Translation of Nouns in Seeing Meng Haoran off at Yellow Crane Tower
}

Tian Dong, Jiaqi Cheng"

English Department, Foreign Language School, North China Electric Power University, Baoding, Hebei, China

DOI: $10.36348 /$ sijll.2020.v03i04.005 $\quad$ | Received: 03.04.2020 | Accepted: 11.04 .2020 | Published: 25.04 .2020

*Corresponding author: Jiaqi Cheng

\section{Abstract}

In recent years, the research on the combination of linguistics and translatology is becoming more and more abundant. This study not only introduces the study of the two subjects, but also explores the problems of gaps in translation process of ancient Chinese poetry. Through the approach of contrastive research, this study analyses the contrast of lexeme and semantic gaps reflected by nouns in ten English versions of Li Bai's poem: Seeing Meng Haoran off at Yellow Crane Tower. Results show that the social and cultural factors behind the naming of nouns are closely related to the emergence of these gaps. Translators should find out exact causes behind those gaps and choose appropriate translation strategies according to the different types of the gaps.

Keywords: The Contrastive Linguistics, nouns' translation, lexical inequality, lexeme gap, semantic gap, Seeing Meng Haoran off at Yellow Crane Tower.

Copyright @ 2020: This is an open-access article distributed under the terms of the Creative Commons Attribution license which permits unrestricted use, distribution, and reproduction in any medium for non-commercial use (NonCommercial, or CC-BY-NC) provided the original author and source are credited.

\section{INTRODUCTION}

In translation studies at home and abroad, researchers are involved in a wide range of fields, from vocabulary to syntax, text level, forming a strict translation system. However, the research on sentence and text level is relatively complete in translation research, while the research on vocabulary, especially on nouns, still has some room for progress. In translation studies, we can easily find some researches focusing on the nominalizations in translations of English and Chinese. However, there are relatively few articles devoted to noun translations with linguistic methods and theories. What's more, among those articles on nouns' translation, most of them are focusing on the study of proper nouns in special fields, such as the translation of proper nouns in medical field and military field, while the study of noun translation in literary works, especially those related to national culture, is rare.

The nouns in ancient Chinese poetry with Chinese traditional culture usually would be expressed succinctly and poetically, which is of great research value. Li Bai's poems are very famous and popular in China, so the number of translations is sufficient for research. Moreover, Li Bai not only has great literary talent in diction but also has abundant knowledge reserve. The nouns used in his poems are often relate to the emotional feelings of the whole poem. Some nouns are closely related to allusions, which can reflect the specific characteristics of Chinese.

With the development of globalization, some new changes have taken place in translatology. In response to the national "outward-oriented" strategy, domestic scholars are constantly exploring the relationship between translation and culture while striving for translation quality. Some scholars have focused on the reorientation of translation and culture [1] and the translator mode and translation strategies in the background of "outward-oriented"[2]. All of these are scholars' new thoughts on how to introduce Chinese literature and culture to the outside world better. Therefore, the study of Li Bai's works is also for the better "going out" of Chinese culture. In view of the above reasons, this paper chooses ten versions of $\mathrm{Li}$ Bai's poem Seeing Meng Haoran off at Yellow Crane Tower to study the original and translated versions of nouns.

\section{LITERATURE REVIEW}

In recent years, the study of translatology not only caters to the tendency of interdisciplinary communication and research, such as the cognitive translatology[3], but also develops critically inside its own discipline. Translation is closely related to 
language and culture, thus the study of translation will naturally play an important role in promoting Chinese culture.

The study of contrastive linguistics is also in the process of communicating and integrating with other disciplines. The method of contrast is not only the most basic method of foreign language learning and research, but also the basis of translation and translation research [4]. In the field of contrastive linguistics, many scholars have proposed the importance of applied contrastive study, and translation is an important direction of its application. Mr. Pan has defined the relationship between translation and contrastive linguistics in his article and he points out that people should see these two subjects as complementary subjects rather than two independent subjects [5].

Contrastive linguistics is mainly based on the analysis of the differences between the two languages in the way of language composition. It has been extended to sentence groups, discourse, rhetoric, style, pragmatics, culture and other levels since the 1990s [6]. In recent years, there has been a contrastive analysis of people's cognition of language. From the perspective of contrastive linguistics, many scholars have carried out the translation practice research of the text, which mainly focuses on the novel text, such as the study of The Scarlet Letter; there are also researches combining contrastive linguistics with language teaching. In this perspective, the contrastive study of the original and translated work of ancient Chinese poetry is lacking.

In the book Contrastive Linguistics Between Chinese and English[7], Chen has divided the problem of lexical inequality between Chinese and English into the following gaps: lexeme gap, semantic gap and usage gap. Among them, the lexeme gap refers to the corresponding entries that in the source language cannot be found in the target language, and the semantic gap refers to that both languages are restricted by specific language forms and loaded with specific cultural connotations. Therefore, semantic gaps often occurs in the process of interlanguage conversion[8]. Semantic gaps are usually related to culture. These gaps mainly point out the differences between the two languages from different perspectives, and these differences are very difficult to reconcile with translation strategies. In the process of language translation, these gaps are the main reasons for the difficulties in translation. The usage gaps usually would appear in dialogue communication, and the corpus selected in this paper is poetry, so this paper will focus on lexeme gaps and semantic gaps.

In addition to the field of contrastive linguistics, "lexeme gap" and "semantic gap" are also the research objects in the field of intercultural communication, and different scholars have different classifications of them. As for the "lexeme gap", it is mentioned that Aixian Guo divides lexeme gaps into material lexeme gaps and cultural lexeme gaps[9]. This kind of classification actually brings semantic gaps into the field of lexeme gaps, and closely connects semantic gaps with cultural background of the languages. And because of the different ways of classification, most of the studies separate "lexeme gap" and "semantic gap". Articles related to "semantic gaps" often appear together with "culture loaded words"[10, 11], and appear in the field of cross-cultural communication for research, which can also reveal that the semantic gap is more related to the level of culture. In fact, the term "culture loaded words" is just another name for "lexeme gap", which means that some words in one language cannot match in another language [9]. While "lexeme gaps" often appear in the field of translation, especially on the field of translation strategies. And among these studies, it is very common to conduct research combined with special terms with these gaps, such as legal terms and TCM terms.

This study uses Dezhang Chen's method of classification [7], and takes both of the lexeme gaps and semantic gaps as the research objects to analyze the corpus in order to be more in line with the cultural content of the corpus and the particularity of the words.

\section{The study of translation gaps of nouns}

This paper selects ten different versions of $\mathrm{Li}$ Bai's poem Seeing Meng Haoran off at Yellow Crane Tower as the corpus, and makes a contrastive study of the nouns and their translations. The writer selects ten versions of ten translators, which are the translations of Yuanchong Xu (the second draft), Dalian Wang, Xianyi Yang and Naidie Dai, Roger Mason, Junpu Chen, Dayu Sun, Peter Cooper Xu, Yanchun Zhao and Chongming Zeng.

In order to make the research more scientific, this paper filters the nouns appearing in the poems and selects the words with research value for analysis.

\section{《黄鹤楼送孟浩然之广陵》 李白 \\ 故人西辞黄鹤楼, 烟花三月下扬州。 孤帆远影碧空尽, 惟见长江天际流。}

In addition to the proper nouns "黄鹤楼", "扬 州" and "长江", there are also normal words like"烟花 ", "三月", "孤帆","远影" , "碧空" and "天际" among which the differences between the translations and the original of such phrases as "孤帆" and "碧空" are relatively tiny, so we choose the "黄鹤楼""长江", "烟 花" and "三月" to analyze.

\section{The Lexeme Gap}

Lexeme gap means that the corresponding entries in the source language cannot be found in the target language. There are several reasons for this 
difference: different motivations behind naming, different ways of grouping things, differences between synonyms and unique cultural phenomena [7].

First of all, from the perspective of different motivations behind naming, we can find this kind of gap in the translation of "长江" in the ten versions of the poem.

\section{Table-1}

\begin{tabular}{|l|l|}
\hline Nouns & Numbers \\
\hline endless River & 2 \\
\hline River & 1 \\
\hline the great river & 2 \\
\hline the Yangtze River & 4 \\
\hline the Long River & 1 \\
\hline
\end{tabular}

For the word "长江", there are five different versions of the ten selected translations. The writer lists the different translations and the frequency of their occurrence in Table 1 . We can see that the most frequent translation is "the Yangtze River", followed by "the Great River" or "endless river".

As one of the "two major rivers", the influence of "长江" is very huge in China. Whether the "长江" in this poem is the "the Yangtze River" that people usually recognize or not is a question that scholars have studied extensively for a long time. Some people think that although the Yellow Crane Tower is on the edge of the Yangtze River, the "长江" in this city is not the "Yangtze River" that people usually recognize, but as a endocentric phrase- "long" is used to modify the "river"[12].

Such ambiguity can explain why translators use five different words to translate this "长江".

Compared with English translation, we can find that such ambiguity will not occur in English, because the modification relationship will be directly reflected in its form, that is, "endless river" and "the Yangtze River". In English, proper nouns usually do not appear in the form of endocentric phrases, even if they do, they will not cause ambiguity, such as "the Great Britain"and "the United States". The rivers and mountains have their own names, such as "Rhine", "Thames", "Mississippi", "Loki", "Kilimanjaro", etc. Some people may think of "the Red Sea" and "the Black Sea" in English. They are indeed proper noun phrases in form of endocentric phrases. However, we can recognize whether this word is a proper noun from the morphological change, that is, the initial capital letters of the phrases. The morphological change of English can reduce the ambiguity of vocabulary.

On the contrary, there is no morphological change in Chinese vocabulary, and since Chinese is a pictograph, it tends to name things according to their surface features, which makes the classification of words such as "the Yellow River", "East China Sea" and "South China Sea" fuzzy and complex, and easy to produce ambiguity while translating.

Secondly, we can see the lexeme gaps caused by the unique cultural phenomenon from the translation of “烟花” and “三月”.

In the selected versions, the writer summarizes the different translations and the frequencies of “烟花” and lists them in Table 2. As shown in Table 2, for the translation of “烟花”, the translators' choices are very scattered, and they do not focus on one same translation on a large scale. Among these translations, most of them are related to "smoke" and "flower".

Table-2

\begin{tabular}{|l|l|}
\hline nouns & numbers \\
\hline willow-down and flowers reign; & 1 \\
\hline green willows and red flowers & 1 \\
\hline misty, flowery ; & 2 \\
\hline mist and flowers & 1 \\
\hline in flower ; & 1 \\
\hline flowery & 1 \\
\hline thriving & 1 \\
\hline catkins & 1 \\
\hline amid flowers & 1 \\
\hline
\end{tabular}

In this poem, "烟花" is obviously not the same as "firecracker" in modern Chinese. From the above data, we can see that The translators' translations of "烟 花 " are quite different. Most translators translate "smoke"（烟） and "flower"（花） separately, or discard "smoke" and only take the meaning of "flower". Some of them translate it into "willow and flower", "willow catkins" or "flourishing and thriving" which are quite different from the original poem.

For the"烟花"in Li Bai's poems, we should first analyze its meaning from the atmosphere embodied in the whole poem. This poem describes a farewell to a friend, but the tone of the whole poem is very positive, and filled with hope and joy. The time of farewell takes place in the vigorous "三月"(March), and the place where the friend will go is Yangzhou, a beautiful water town in the south of the Yangtze River, so the "烟花" here should be the same as the tone of the whole poem, reflecting the image of energy and vitality of natural creatures. It can be seen that "mist" usually gives people a sense of mystery and obscurity, which is contrary to the bright tone of this poem, so it is not appropriate to translate it into "mist". It is analyzed that "烟花"in Li Bai's poem actually refers to "琼花", a kind of flower distributed in the south of China. It usually blooms from April to May in spring. The flower is as big as a plate and as white as jade. Therefore, when this kind of flowers in the time of full blooming, it will 
create a vast white landscape, which is similar to the color of smoke, so it is described as "烟" (smoke) by Li Bai.

The lexeme gap caused by the unique cultural phenomena is very common. In Li Bai's ascending the Phoenix Terrace of Jinling City, "Wu Palace" refers to the allusion that Sun $\mathrm{Wu}$ built a palace in the capital of Jinling in the Three Kingdoms Era. Without this cultural background, native English readers who have no knowledge of Chinese language background would possibly be confused by the English version "Wu Palace" (Dayu Sun) and "the dynastic house of the Go"(Pound).

For the translation of "三月", the writer lists its translation and frequency in Table 3 . It is found that translators' translations of "March" are different, most of which focus on the translation between "April" and "March".

Table-3

\begin{tabular}{|l|l|}
\hline Nouns & Numbers \\
\hline Ellipsis & 2 \\
\hline May & 1 \\
\hline spring & 1 \\
\hline April & 3 \\
\hline March & 3 \\
\hline
\end{tabular}

The months usually used in Chinese classical poetry is based on the lunar calendar, so "三月"(March) in this poems actually refers to the "March" of the lunar calendar, which is the "April" in the universal calendar. If the translators want to translate "March" accurately, they need to interpret it as "March in traditional Chinese lunar calendar". Therefore, some poetry translators have noticed such differences and translated "March" into "April". Some translators have cleverly translated the month into "spring", so as to avoid the mistakes caused by the confusion of the months, and the season of spring could fit the tone of the whole poem, therefore this choice is obviously reasonable. However, Dalian Wang's translation into "May" is to echo the rhyme produced by the "way" in the above verse, but this translation would actually cause meaning differences from the original, thus create the translation errors.

\section{The Semantic Gap}

Semantic gap mainly includes three parts: referential meaning, extended meaning and semantic direction. The semantic gap between referential meanings is mainly generated from the semantic gap between words and their referents. The semantic gap between extended meanings is usually the difference between the additional meanings of words with the development of society, while the semantic direction gap is the difference between the meanings of words including time and space, expression logic and emotional direction [7].
Table-4

\begin{tabular}{|l|l|}
\hline nouns & numbers \\
\hline yellow crane tower & 8 \\
\hline towers yellow crane & 1 \\
\hline yellow crane towers & 1 \\
\hline
\end{tabular}

We can take the translation of the "黄鹤楼"as an example. It can be seen from the above table that the official translation name of "黄鹤楼"—— the "Yellow Crane Tower" is used by most translators, and a relatively small number of translation versions appear in Yuanchong Xu's two translations. This kind of translation method is mainly for the aim of rhyme, and there is no obvious lexical difference with most of the translation versions.

The Yellow Crane Tower, located in the downstream Yangtze River in Wuhan, Hubei Province, has become a famous cultural relic in China due to its long history and popular legends. Until now, the tower has attracted numerous people. In fact, the Yellow Crane Tower in this poem is not only a scenic spot, a building for literati to visit during the Tang Dynasty, but also a symbol of farewell and departure.

The poet chooses "Yellow Crane Tower" as the description object, which is related to the legend that "the immortal son named Zi' an lives in the Yellow Crane Tower and rides the crane to climb the immortal". "Crane" has the extended meaning of "leaving" in Chinese, "driving the crane to the west" and other idioms express the connection between "crane" and the image of "ascending to the immortals and passing away". Li Bai wrote in another poem "the Yellow Crane Tower has been smashed, and the Yellow Crane immortal has no place to rely on." (黄鹤高楼已 捶碎, 黄鹤仙人无所依) It can also prove that the role of Yellow Crane Tower in this poem is not only to point out the place where the friend of the poet leaves, but also to reveal the poet's hint of his friend's departure. It also expresses the poet's comparison between his friend and the immortals, which shows his casual and unrestrained attitude towards life and optimistic mind.

In English, the word "crane" does not produce the same image as it in Chinese. Crane only represents a kind of bird in English. The main reason for this difference is that the different extended meanings lead to the different expressions of intention in Chinese and English. "Crane" is the most widely distributed animal in East Asia, while China is the country with the largest number of cranes. Therefore, Chinese people have a very deep feeling for "crane", and the appearance of "crane" is beautiful, the voice is melodious and the dance is elegant, giving people an image of "high-status and elegant", which is very consistent with the "beauty and virtue of gentlemen" advocated by Chinese people. Therefore, Chinese people will give "crane" much more 
rich extended meanings. The difference between the extended meanings of these words can also be reflected in "Nightingale" and "Owl" in English. These two kinds of images often appear in English poetry, but rarely in Chinese poetry. Because they are also two kinds of birds that often appear in the western world, they are endowed with rich extended meanings by the people living in the west society.

Therefore, although the official translation of " 黄鹤楼" is the "yellow crane tower", its meaning is different from that of the original poem in the extended meaning. In the process of translation, the translator needs to annotate the extended meaning, and the reader needs to understand the cultural differences between the two sides. Cultural understanding is necessary for both translators and readers.

\section{RESULTS AND DISCUSSION}

From the perspective of contrastive linguistics and the theory of translation gaps, this study analyzes ten English versions of Li Bai's poem Seeing Meng Haoran off at Yellow Crane Tower from two types of gaps. Through analyzing the number of versions in different translations of same noun, we find that the phenomenon of lexical inequality is embodied in the process of translation. In the future, the field of noun translation still needs us to dig more with abundant corpus, and we also need to combine with more subjects, such as sociolinguistics, to deeply explore the social and cultural reasons behind the phenomenon of lexical inequality.

\section{CONCLUSION}

Lexeme and semantic gaps are reflected in various aspects in ancient Chinese poetry, which is closely related to cultural and social elements. This fact proves that in the process of Chinese-English translation, translators should be guided by the exact reasons behind those gaps, choose appropriate strategies in translation practice, and reduce the phenomena of mis-translation and omission caused by those gaps.

\section{REFERENCES}

1. Ning. W. (2013). Translation and Cultural Reorientation [J]. Chinese Translation, 34(02): 511,127

2. Anjiang, H.U.(2010). A Study on the Translator Mode and Translation Strategy of "Going Global" in Chinese Literature: a Case Study of Haowen $\mathrm{Ge}$ [J]. Chinese Translation, 31(06): 10-16, 92

3. Yin, W.(2012). Cognitive Translation Research [J]. Chinese Translation, 33(04): 17-23, 127

4. Wenguo, P. (2019). Basic Methods and Innovations of Contrastive Study of English and Chinese [J]. Foreign Language Teaching, 40(01): 1-6

5. Wenguo, P. (2007). Translation and Contrastive Linguistics [J]. Journal of Shanghai University (social sciences edition), 2007 (01): 114-117

6. Zijian, Y.(1999). Some Problems in Contrastive Linguistics $[\mathrm{J}]$. Journal of Qingdao Ocean University (social science edition), 02: 77-82

7. Chen, D. (2011). Contrastive Linguistics between Chinese and English.

8. Jianhua, S.(2019). Parody and Precedent: Semantic Gaps and Translation [J]. Journal of Graduate Students in Central China Normal University, 26(01): 106-110

9. Aixian, G.(1998). Lexical Gaps and Their Translatability $[\mathrm{J}]$. Journal of PLA Foreign Languages Institute, 05: 43-45, 67

10. Xiaodan, C.(2010). Classification and Translation of Culture Loaded Words from the Perspective of Semantic Gaps [J]. Journal of Qinghai University for Nationalities (education science edition), 30(6): 106-108

11. Yuguo, Y. (2019). An Analysis of the Translation of Culture Loaded Words in Legend of the Condor Heroes from the Perspective of Semantic Gaps [D]. Beijing Foreign Studies University.

12. Min, D. (2009). "Faithfulness, Expressiveness and Elegance" in Poetry Translation: Seeing Meng Haoran off at Yellow Crane Tower [J]. Journal of Zibo Teachers' College. (1): 43-45, 48. 